\title{
The Benefits and Challenges of Using Patient Decision Aids to Support Shared Decision Making in Health Care
}

Citation for published version (APA):

Ankolekar, A., Dekker, A., Fijten, R., \& Berlanga, A. (2018). The Benefits and Challenges of Using Patient Decision Aids to Support Shared Decision Making in Health Care. JCO Clinical Cancer Informatics, 2, 1-9. https://doi.org/10.1200/CCl.18.00013

Document status and date:

Published: 09/11/2018

DOI:

10.1200/CCI.18.00013

Document Version:

Publisher's PDF, also known as Version of record

Document license:

Taverne

Please check the document version of this publication:

- A submitted manuscript is the version of the article upon submission and before peer-review. There can be important differences between the submitted version and the official published version of record.

People interested in the research are advised to contact the author for the final version of the publication, or visit the DOI to the publisher's website.

- The final author version and the galley proof are versions of the publication after peer review.

- The final published version features the final layout of the paper including the volume, issue and page numbers.

Link to publication

\footnotetext{
General rights rights.

- You may freely distribute the URL identifying the publication in the public portal. please follow below link for the End User Agreement:

www.umlib.nl/taverne-license

Take down policy

If you believe that this document breaches copyright please contact us at:

repository@maastrichtuniversity.nl

providing details and we will investigate your claim.
}

Copyright and moral rights for the publications made accessible in the public portal are retained by the authors and/or other copyright owners and it is a condition of accessing publications that users recognise and abide by the legal requirements associated with these

- Users may download and print one copy of any publication from the public portal for the purpose of private study or research.

- You may not further distribute the material or use it for any profit-making activity or commercial gain

If the publication is distributed under the terms of Article $25 \mathrm{fa}$ of the Dutch Copyright Act, indicated by the "Taverne" license above, 


\title{
The Benefits and Challenges of Using Patient Decision Aids to Support Shared Decision Making in Health Care
}

\begin{abstract}
Shared decision making (SDM) and patient-centered care require patients to actively participate in the decision-making process. Yet with the increasing number and complexity of cancer treatment options, it can be a challenge for patients to evaluate clinical information and make riskbenefit trade-offs to choose the most appropriate treatment. Clinicians face time constraints and communication challenges, which can further hamper the SDM process. In this article, we review patient decision aids (PDAs) as a means of supporting SDM by presenting clinical information and risk data to patients in a format that is accessible and easy to understand. We outline the benefits and limitations of PDAs as well as the challenges in their development, such as a lengthy and complex development process and implementation obstacles. Lastly, we discuss future trends and how change on multiple levels-PDA developers, clinicians, hospital administrators, and health care insurers-can support the use of PDAs and consequently SDM. Through this multipronged approach, patients can be empowered to take an active role in their health and choose treatments that are in line with their values.
\end{abstract}

Clin Cancer Inform. @ 2018 by American Society of Clinical Oncology

\section{INTRODUCTION}

The health care landscape is undergoing rapid advances in the amount and type of clinical data collected, analyzed, and shared. In addition, patients and consumers now have access to a greater range of information through the Internet and are willing and able to take on a more active role in their health. These trends are

Anshu Ankolekar

Andre Dekker

Rianne Fijten

Adriana Berlanga

Author affiliations and support information (if applicable) appear at the end of this article.

Corresponding author: Anshu Ankolekar, Department of Radiation Oncology, GROW School for Oncology and Developmental Biology, Maastricht University Medical Centre, Dr Tanslaan 12, 6229ET, Maastricht, the Netherlands; e-mail: anshu.ankolekar@ maastro.nl. leading to the evolution of P4 medicine-health care that is personalized, preventive, predictive, and participatory. ${ }^{1} \mathrm{P} 4$ medicine has the potential to improve patient outcomes and clinical interactions in which both the patient and clinician have access to data that are accurate, relevant, and evidence based. In addition, P4 medicine may reduce the increasing costs of health care, for instance, by stratifying patients according to their personal characteristics, which allows for more targeted therapies and potentially less invasive and expensive treatment decisions. ${ }^{2}$

Operationalizing P4 medicine will involve confronting both technological and societal challenges. The complexity of decision making in oncology forces patients and clinicians to consider the pros and cons of an increasing number of treatment options. ${ }^{3}$ In addition, patients evaluate their treatment options differently from their clinicians. For instance, patients with breast cancer were found to consider multiple factors in their decision making, such as the impact on daily life, maintaining fertility, and adverse effects, whereas clinicians tended to focus more on survival. ${ }^{4}$ Furthermore, when faced with making choices under conditions of uncertainty, both patients and clinicians are susceptible to bias and reliance on heuristics. ${ }^{5}$ Many patients face difficulty in forecasting their future ${ }^{6}$ and often lack the skills to interpret risk figures and probabilities. 7,8 Patients and clinicians will need new ways of collaborating to evaluate all relevant pieces of evidence and personal preferences to make optimal choices.

The shared decision-making (SDM) paradigm emerged as a way to consolidate the wishes of both parties-the patient and the clinician. ${ }^{9}$ Under the traditional paternalistic model, information flows one way from the clinician to the patient, deliberation on treatment options largely involves the main clinician and other medical staff, and the final decision is made by the clinician with little or no input from the patient. High-quality SDM is based on three pillars ${ }^{10}$ : two-way information sharing between the patient and clinician, deliberation on the basis of the 
patient's preferences, and the involvement of both the patient and clinician in the final decisionmaking process. SDM has been associated with less decisional regret and lower anxiety about treatment choices, better health outcomes, and greater patient satisfaction ${ }^{11}$; however, as with any new innovation, implementing SDM requires adjustments by health care professionals to overcome barriers, such as time constraints, a perceived lack of applicability in certain cases, and cultural changes. ${ }^{12}$

Patient decision aids (PDAs) have been developed as a way to support patient participation in the decision-making process and to increase the likelihood of reaching a treatment decision that is both clinically sound and in line with patients' values. A PDA is any tool-booklet, Web site, or application-that helps the patient understand his or her treatment options to make an informed decision. ${ }^{13}$ A well-designed PDA provides balanced information on treatment benefits and risks and can help patients identify and reflect on their personal preferences. PDAs are particularly useful in disease areas that have multiple treatment options with different outcomes and adverse effects. ${ }^{14}$

The objective of this review is to gather and assess evidence of the role of PDAs in supporting the SDM process. We begin by reviewing the types of PDAs and their benefits and limitations. We then describe the development process and its associated challenges. We end with a brief exploration of future trends in light of the changing technological and social landscape and what is needed to build a stronger evidence base to aid in the development and implementation of PDAs.

\section{BENEFITS AND LIMITATIONS OF PDAS}

PDAs can guide a variety of health care decisions that range from screening decisions and treatment decisions to post-treatment follow-up (an alphabetical list of PDAs according to disease type has been created by the Ottawa Hospital Research Institute ${ }^{15}$ ). A typical PDA contains the following: information about the disease type; treatment options; risks, benefits, and uncertainties associated with each option; and a form of value clarification exercise in which patients are asked to make choices the basis of the tradeoffs between the treatment options and risks. The purpose of value clarification is to allow patients to reflect on what aspects of the treatment options matter most to them so that it is easier for clinicians to engage with patients and guide the decision-making process toward the most ideal outcome.

Use of PDAs has been shown to improve care quality on several dimensions, per evidence from a Cochrane review of 105 randomized controlled trials (RCTs) across 10 countries. ${ }^{16}$ In 52 RCTs, patients who used a PDA scored higher on knowledge tests than those who received standard care, and in 17 RCTs were able to interpret risks more accurately. By helping patients become more informed, PDAs can also improve the quality of the clinical interaction and communication between patients and clinicians; five RCTs report that PDA users demonstrated statistically significant increases in OPTION (observing patient involvement in decision making) scores, a method used to evaluate clinical interactions on the basis of SDM principles. Furthermore, patients took on a more active role in decision making when they used a PDA compared with standard care, as demonstrated in 15 RCTs.

Whereas there is abundant evidence of the clinical benefits of PDAs, a considerable gap exists in the literature with regard to their economic viability. Development and implementation involves upfront costs - time, labor, and resources. One feasibility study summed up the time and costs associated with one staff member delivering a PDA to 268 patients over a 5-month period and found that the total time spent in the clinical encounter, including time spent reviewing patients' medical records, amounted to an additional 292 hours - 65 minutes per patient on average. ${ }^{17}$ There is a lack of similar studies to corroborate this finding, although evidence from 10 RCTs suggests that PDAs increase consultation times slightly. ${ }^{18}$

In contrast, other evidence asserts that PDAs have the potential to reduce costs in the long term as patients may choose less aggressive treatments when provided with more information about each treatment. ${ }^{11,19}$ Indeed, up to $20 \%$ of patients who use PDAs choose less-invasive procedures and more conservative therapies. ${ }^{20}$ For instance, use of a PDA for hip and knee replacement decisions resulted in $26 \%$ fewer hip replacements, $38 \%$ fewer knee replacements, and an overall cost reduction of up to $21 \%$ over a 6-month period. ${ }^{21}$ Another study 
that was prepared for the Commonwealth Fund predicted that the implementation of PDAs in 11 treatment areas could result in net savings of more than $\$ 7$ billion over a 10 -year period. ${ }^{22}$ Yet a systematic review of the economic evaluation of PDAs demonstrates limited evidence of cost effectiveness over the long term. ${ }^{23-25}$ More evidence is needed to demonstrate potential costs savings.

Lastly, although most PDAs follow a similar format, they can vary widely in terms of the way the content is presented, ${ }^{26-28}$ and there is little consensus on which representation is most effective. For instance, developers might assume that it is better to include as much information as possible; however, too much information can lead to cognitive overload and contribute to suboptimal decision making. ${ }^{29}$ In addition, most PDAs are designed for the patient to use at home and it is not always possible to monitor the uptake of information and determine the effect in consultation. ${ }^{30,31}$ Together with the fact that PDAs are frequently outdated, ${ }^{32}$ it is a challenge to develop and implement high-quality PDAs that can be routinely used in practice. ${ }^{33}$

\section{THE DEVELOPMENT OF PDAS}

The International Patient Decision Aid Standards (IPDAS) were established in 2003 by an international team of researchers and practitioners to create consensus on quality standards between PDA developers around the world. The proposed guidelines for developing PDAs are summarized in Figure 1. The first step of this process is to determine the scope of the decision aid, such as disease area, decision to be made, and target population. Next, a steering group is formed that consists of stakeholders who have expertise in the decision area, such as clinicians, patients, patient advocacy groups, researchers, or policy makers. The steering group oversees the development process, which consists of the following elements: assessing patients' decisional needs, systematically reviewing and synthesizing the literature, developing a distribution plan for the PDA, developing prototypes, and conducting alpha and beta testing of prototypes.

Determining patients' decisional needs is a foundational step in developing an effective PDA for several reasons. First, patients evaluate their treatment options differently than clinicians. ${ }^{35}$ In addition, patient populations are heterogenous and one patient's informational needs may differ significantly from those of another. ${ }^{36}$ As a result, it is important to gain a range of perspectives on the type and quantity of information that patients need to evaluate their options. Patients, clinicians, and advocacy groups can be valuable sources of data and are typically engaged through focus groups, surveys, and interviews.

Once the main decisional needs have been established and incorporated into the initial prototypes, these prototypes must be tested. IPDAS guidelines recommend initial alpha tests among patients and clinicians in a laboratory setting, then broader beta testing in a real clinical practice setting. Finally, implementation must be evaluated using appropriate performance metricsfor example, the extent of use of the decision tool (ie, the number of patients who used the tool as a proportion of those who were eligible to use it) or improvements in the quality of decision support provided by the clinician as measured by the Decision Support Analysis Tool. ${ }^{37}$

IPDAS guidelines represent a standardized development process that can reduce variability in the quality of PDAs; however, questions have been raised about its validity in practice. For instance, as a result of a lack of input from the field of decision science, little is known about which specific components of the IPDAS guidelines best facilitate the decision-making process. ${ }^{38}$ Gaps have also been identified in the evidence base on presenting probabilistic information. ${ }^{39}$ Furthermore, a well-designed PDA may not improve clinical outcomes unless it is properly implemented in clinical practice. Consequently, there are challenges for PDA developers, clinicians, hospital administrators, and the wider health care system.

\section{CHALLENGES IN THE DEVELOPMENT AND IMPLEMENTATION OF PDAS}

The main challenges for PDA developers arise in the improvement of PDA usability, accuracy, and acceptability. Usability challenges include presenting information, particularly on risks and probabilities, in a way that is easy to understand by the general population. Low numeracy levels affect the ability of patients to interpret risk information correctly, ${ }^{40}$ and numeracy tends to decline with age. ${ }^{41,42}$ PDA developers need to consider evidence-based methods of different ways to communicate risks other than 
Fig 1. An International Patient Decision Aid Standards model for the development process for a patient decision aid. Reprinted with permission from Coulter et al. ${ }^{34}$

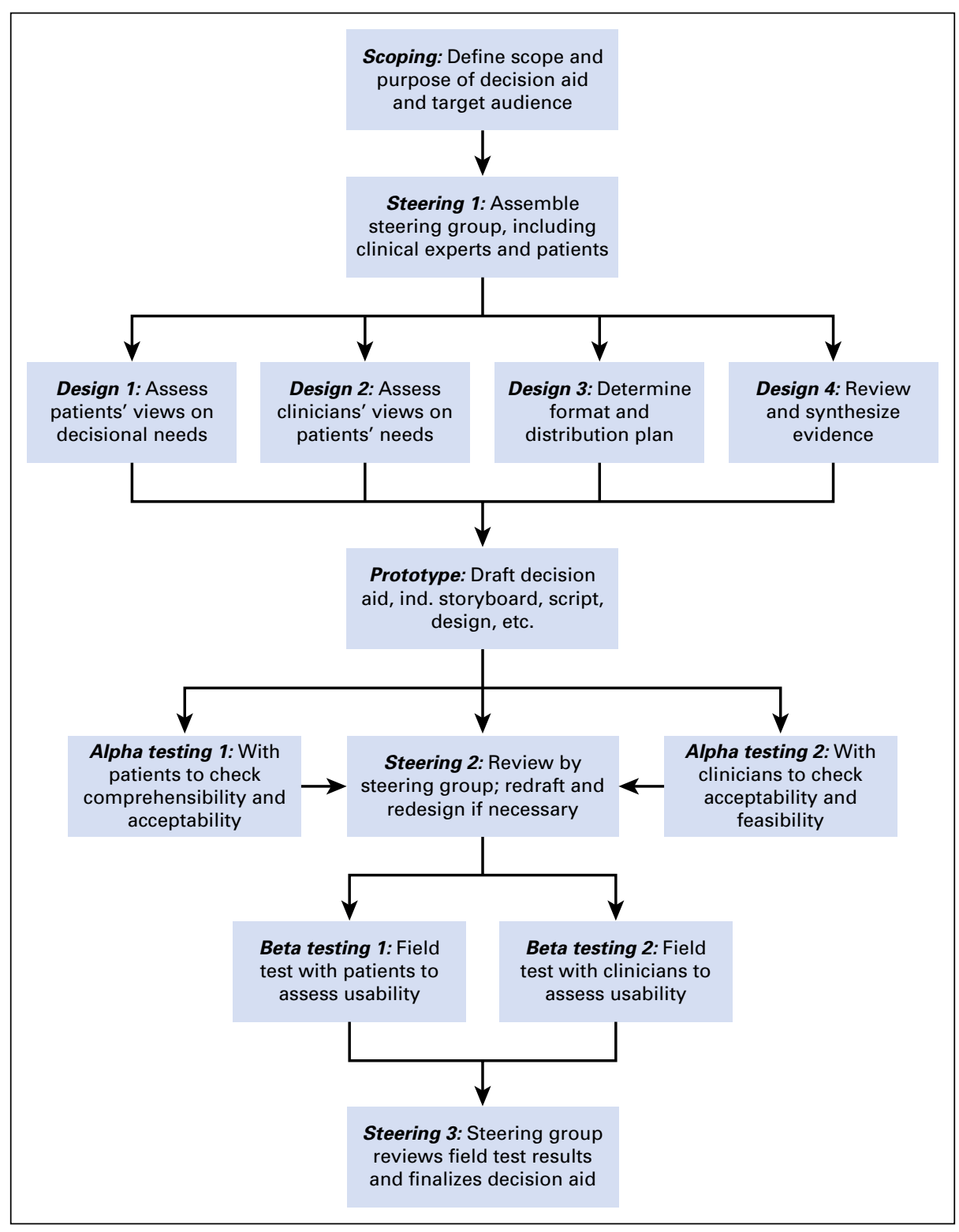

numerically - for instance, through visual aids, graphs, and patient narratives. ${ }^{43}$ An additional challenge for developers is designing PDAs that are accepted by clinicians and do not increase their workloads, as time constraints are the most often-cited barrier to SDM and PDA use. ${ }^{44}$ Clinicians are also less likely to use or recommend a PDA if they feel it does not contain accurate data. User-centered design can help mitigate these factors ${ }^{45}$ and is based on the principle that an innovation is more likely to be successful when its users are consulted in an iterative process, ${ }^{46-48}$ in contrast to the relatively linear design approach in current IPDAS guidelines. There is little guidance in the current literature on user-centered PDA design, although developers can seek insights from its application in other fields that involve human-computer interaction. ${ }^{49-51}$

Clinicians may need to develop new skills in guiding decisional talk that acknowledge the expanded role of the patient in the SDM process. Prior findings suggest two main skill categories: relational competencies (creating quality interactions between clinicians and patients) and risk communication competencies (helping patients understand treatment options and risks). ${ }^{52}$ Relational competencies, such as effective communication, can be developed through training courses, e-learning, or virtual patients to familiarize doctors with the core components of SDM. Risk communication competencies 
involve developing suitable ways to conceptualize the treatment-associated probabilities within decisional talk beyond the contents of PDAs.

Hospital administrators may also play a key role in integrating PDAs and SDM into the clinical workflow to achieve the highest degree of effectiveness. ${ }^{53}$ As the use of electronic health records (EHRs) becomes commonplace, ${ }^{54}$ integrating PDAs into the hospital's EHR system to varying degrees could be a key step. ${ }^{55}$ For instance, the EHR could simply remind clinicians to give patients access to the PDA. One step further, the output of the PDA could be sent automatically to the EHR, which would allow the clinician to see the patient's results, preferences, and any questions to be addressed in advance of the next consultation. The EHR system could also keep track of which data have been filled in and what is missing, providing a more complete overview of the patient's clinical and personal information. Implementing these changes requires developers to collaborate with the hospital's information technology department to integrate the PDA into the existing EHR system. Roles and responsibilities must also be clearly defined so that the PDA can be routinely maintained and updated to reflect the latest evidence.

Finally, although SDM is largely centered on the interaction between health care professionals and patients, other parties outside the clinical setting can also support its implementation. Health care insurers can create incentives for the use of decision support systems by providing reimbursement for the use of decision aids or by making SDM a prerequisite for reimbursing certain procedures. Organizations for patients with cancer can be instrumental in raising awareness among patients and the public about their potential role in the clinical decision-making process as well as in the promotion of PDAs. Finally, the evaluation and dissemination of SDM outcomes can be seen as a quality indicator for care providers and could increase the acceptance of PDAs by health care professionals.

\section{FUTURE TRENDS}

The issues outlined so far reveal the need for a stronger evidence base regarding the development, implementation, and cost effectiveness of PDAs. Measurement remains a methodologic challenge, ${ }^{56}$ and the validity of current evaluation measures, such as patient satisfaction and decisional conflict, has not yet been definitively established, ${ }^{57}$ possibly because of a lack of patient involvement in the development of these instruments. Such methods as cognitive interviewing may be valuable for the development of more patient-centered outcome measurements. ${ }^{58}$ Furthermore, existing models for economic evaluation of PDAs may need to be extended to account for long-term effects and quality-adjusted life-years. ${ }^{59}$

Developers, patients, and health care professionals will also need to adapt to the rapidly changing technological landscape. As computing power and the amount of data generated continue to increase, data analytics and machine learning techniques will allow researchers to identify patterns in medical data that can help predict treatment outcomes. ${ }^{60}$ These prediction models can be used to quantify the likelihood of a specific outcome for a specific patient on the basis of individual risk factors, and can ultimately support personalized decision making. ${ }^{61}$ When aggregated and analyzed over large populations, these data could allow individual patients to compare the choices of patients who are similar to them. Key challenges for developers, clinicians, and hospital administrators are to develop a standardized method of aggregating data across different hospital systems, regions, and countries while protecting patient privacy ${ }^{62}$ and embedding the resulting prediction models into PDAs. In addition, mobile technology has become more accessible than Web-based applications, ${ }^{63}$ and this trend will require developers to adapt PDAs to multiple platforms — smartphones and tablets - and across different patient demographics, particularly elderly patients ${ }^{64,65}$ and those with lower health literacy. ${ }^{66}$

\section{CONCLUSION}

PDAs have the potential to improve health outcomes by presenting complex medical information in a form that allows patients and clinicians to collaborate more effectively. Through multimedia_images, videos, and animationsPDAs can help patients understand disease information and treatment procedures and their risks and benefits. Interactive PDAs also allow patients to weigh different treatment options to clarify their personal preferences. Results can be used to guide clinical interactions in a more balanced process in which patients are 
better informed and clinicians take into account patients' values. Good design is a crucial element for the realization of this potential.

User-centered design methods can enhance PDA quality and acceptability and improve the likelihood of successful adoption. Patients, clinicians, nurses, hospital administrators, and researchers must be engaged in a multidisciplinary process, as sound decision making extends beyond the patient-clinician interaction. In addition to developing high-quality PDAs, the environment needs to be conducive to their implementation. An understanding of the existing workflow within the hospital is needed so that the PDA can be integrated smoothly. In addition, decision makers must be incentivized to engage in SDM and use PDAs. This can be stimulated directly through reimbursement schemes and indirectly by systematic measurement and dissemination of PDA use outcomes to increase the evidence base. The increasing prominence of data analytics in medical decision making requires a paradigm shift in the health care industry on multiple levels - clinical, administrative, policy, and service mind oriented.

DOI: https://doi.org/10.1200/CCl.18.00013

Published online on ascopubs.org/journal/cci on

November 9, 2018.

\section{AUTHOR CONTRIBUTIONS}

Conception and design: All authors

Collection and assembly of data: Anshu Ankolekar, Rianne Fijten, Adriana Berlanga

Data analysis and interpretation: Anshu Ankolekar, Rianne

Fijten, Adriana Berlanga

Manuscript writing: All authors

Final approval of manuscript: All authors

Accountable for all aspects of the work: All authors

\section{AUTHORS' DISCLOSURES OF \\ POTENTIAL CONFLICTS OF INTEREST}

The following represents disclosure information provided by authors of this manuscript. All relationships are considered compensated. Relationships are self-held unless noted. I = Immediate Family Member, Inst = My Institution. Relationships may not relate to the subject matter of this manuscript. For more information about ASCO's conflict of interest policy, please refer to www. asco.org/rwc or ascopubs.org/jco/site/ifc.

Anshu Ankolekar

No relationship to disclose

Andre Dekker

Employment: Medical Data Works B.V.

Stock and Other Ownership Interests: Medical Data Works B.V.

Honoraria: Varian Medical Systems

Consulting or Advisory Role: Varian Medical Systems

Research Funding: Varian Medical Systems (Inst), Philips

Healthcare (Inst), OncoRadiomics (Inst)
Patents, Royalties, Other Intellectual Property: Royalties
from Mirada Medical for a deep learning application in
medical imaging (Inst); royalties from Varian Medical
Systems for dosimetry software for radiation oncology
(Inst); royalties from Health Innovation Ventures for
Radiomics, e-learning, and prediction models in cancer
(Inst); royalties from PXI for software related to small
animal irradiation for life sciences research (Inst); patents
for monitoring respiration on the basis of plethysmographic
heart rate signal (US patent $6,702,752$ ); apparatus and
method for monitoring respiration with a pulse oximeter
(US patent 6,709,402); monitoring mayer wave effects
on the basis of a photoplethysmographic signal (US
patent $6,805,673)$; monitoring physiologic parameters
on the basis of variations in a photoplethysmographic
baseline signal (US patent $6,896,661$ ); monitoring
physiologic parameters on the basis of variations in a
photoplethysmographic signal (US patent $7,001,337$ );
knowledge-based interpretable predictive model for
survival analysis (US patent $8,078,554$ ); dose distribution
modeling by region from functional imaging (US patent
$8,812,240$ ); systems, methods, and devices for analyzing
quantitative information obtained from radiologic images
(US patent 9721340 B2)
Expert Testimony: Thoratec
Travel, Accommodations, Expenses: Medical Data Works B.V.

Rianne Fijten

No relationship to disclose

Adriana Berlanga

No relationship to disclose

\section{Affiliations}

Anshu Ankolekar, Andre Dekker, and Rianne Fijten, Maastricht University Medical Centre, Maastricht; and Adriana Berlanga, Maastricht University, Maastricht, the Netherlands.

\section{REFERENCES}

1. Hood L, Friend SH: Predictive, personalized, preventive, participatory (P4) cancer medicine. Nat Rev Clin Oncol 8:184-187, 2011

2. Hood L, Galas D: P4 medicine: Personalized, predictive, preventive, participatory-A change of view that changes everything. https://cra.org/ccc/wp-content/uploads/sites/2/2015/05/P4_ Medicine.pdf 
3. Reyna VF, Nelson WL, Han PK, et al: Decision making and cancer. Am Psychol 70:105-118, 2015

4. Lee CN, Dominik R, Levin CA, et al: Development of instruments to measure the quality of breast cancer treatment decisions. Health Expect 13:258-272, 2010

5. Tversky A, Kahneman D: Advances in prospect theory: Cumulative representation of uncertainty. J Risk Uncertain 5:297-323, 1992

6. Redelmeier DA, Rozin P, Kahneman D: Understanding patients' decisions. Cognitive and emotional perspectives. JAMA 270:72-76, 1993

7. Mazur DJ, Hickam DH: Patient interpretations of terms connoting low probabilities when communicating about surgical risk. Theor Surg 8:143-145, 1993

8. Woloshin S, Schwartz LM, Moncur M, et al: Assessing values for health: Numeracy matters. Med Decis Making 21:382-390, 2001

9. Charles C, Gafni A, Whelan T: Decision-making in the physician-patient encounter: Revisiting the shared treatment decision-making model. Soc Sci Med 49:651-661, 1999

10. Charles C, Gafni A, Whelan T: Shared decision-making in the medical encounter: What does it mean? (or it takes at least two to tango). Soc Sci Med 44:681-692, 1997

11. Oshima Lee E, Emanuel EJ: Shared decision making to improve care and reduce costs. N Engl J Med 368:6-8, 2013

12. Gravel K, Légaré F, Graham ID: Barriers and facilitators to implementing shared decision-making in clinical practice: A systematic review of health professionals' perceptions. Implement Sci 1:16, 2006

13. Ruland CM: Improving patient safety through informatics tools for shared decision making and risk communication. Int J Med Inform 73:551-557, 2004

14. O'Connor A: Using patient decision aids to promote evidence-based decision making. ACP J Club 135:A11-A12, 2001

15. The Ottawa Hospital Research Institute: Alphabetical list of decision aids by topic. https:// decisionaid.ohri.ca/AZlist.html

16. Stacey $D$, Légaré $F$, Lewis $K$, et al: Decision aids for people facing health treatment or screening decisions. Cochrane Database Syst Rev 4:CD001431, 2017

17. Miller KM, Brenner A, Griffith JM, et al: Promoting decision aid use in primary care using a staff member for delivery. Patient Educ Couns 86:189-194, 2012

18. Bekker HL, Hewison J, Thornton JG: Applying decision analysis to facilitate informed decision making about prenatal diagnosis for Down syndrome: A randomised controlled trial. Prenat Diagn 24:265-275, 2004

19. Knops AM, Legemate DA, Goossens A, et al: Decision aids for patients facing a surgical treatment decision: A systematic review and meta-analysis. Ann Surg 257:860-866, 2013

20. Stacey D, Bennett CL, Barry MJ, et al: Decision aids for people facing health treatment or screening decisions. Cochrane Database Syst Rev 2011:CD001431, 2011

21. Arterburn D, Wellman R, Westbrook E, et al: Introducing decision aids at Group Health was linked to sharply lower hip and knee surgery rates and costs. Health Aff (Millwood) 31:20942104, 2012

22. Schoen C, Guterman S, Shih A, et al: Bending the Curve: Options for Achieving Savings and Improving Value in US Health Spending. New York, NY, The Commonwealth Fund, 2007

23. Trenaman L, Bryan S, Bansback N: The cost-effectiveness of patient decision aids: A systematic review. Healthc (Amst) 2:251-257, 2014

24. Kennedy AD, Sculpher MJ, Coulter A, et al: Effects of decision aids for menorrhagia on treatment choices, health outcomes, and costs: A randomized controlled trial. JAMA 288:2701-2708, 2002 
25. Walsh T, Barr PJ, Thompson R, et al: Undetermined impact of patient decision support interventions on healthcare costs and savings: Systematic review. BMJ 348:g188, 2014

26. Raats CJ, van Veenendaal H, Versluijs MM, et al: A generic tool for development of decision aids based on clinical practice guidelines. Patient Educ Couns 73:413-417, 2008

27. O'Connor AM, Drake ER, Fiset V, et al: The Ottawa patient decision aids. Eff Clin Pract 2:163-170, 1999

28. Elwyn G, Kreuwel I, Durand MA, et al: How to develop web-based decision support interventions for patients: A process map. Patient Educ Couns 82:260-265, 2011

29. Peters E, Klein W, Kaufman A, et al: More is not always better: Intuitions about effective public policy can lead to unintended consequences. Soc Issues Policy Rev 7:114-148, 2013

30. Hargraves I, Montori VM: Decision aids, empowerment, and shared decision making. BMJ 349:g5811, 2014

31. Agoritsas T, Heen AF, Brandt L, et al: Decision aids that really promote shared decision making: The pace quickens. BMJ 350:g7624, 2015

32. Montori VM, LeBlanc A, Buchholz A, et al: Basing information on comprehensive, critically appraised, and up-to-date syntheses of the scientific evidence: A quality dimension of the International Patient Decision Aid Standards. BMC Med Inform Decis Mak 13:S5, 2013

33. Elwyn G, Légaré F, van der Weijden T, et al: Arduous implementation: Does the Normalisation Process Model explain why it's so difficult to embed decision support technologies for patients in routine clinical practice. Implement Sci 3:57, 2008

34. Coulter A, Stilwell D, Kryworuchko J, et al: A systematic development process for patient decision aids. BMC Med Inform Decis Mak 13:S2, 2013 (suppl 2)

35. Turner S, Maher EJ, Young T, et al: What are the information priorities for cancer patients involved in treatment decisions? An experienced surrogate study in Hodgkin's disease. Br J Cancer 73:222-227, 1996

36. Feldman-Stewart D, Brundage MD, Nickel JC, et al: The information required by patients with early-stage prostate cancer in choosing their treatment. BJU Int 87:218-223, 2001

37. Butow P, Juraskova I, Chang S, et al: Shared decision making coding systems: How do they compare in the oncology context? Patient Educ Couns 78:261-268, 2010

38. Bekker HL: The loss of reason in patient decision aid research: Do checklists damage the quality of informed choice interventions? Patient Educ Couns 78:357-364, 2010

39. McDonald H, Charles C, Gafni A: Assessing the conceptual clarity and evidence base of quality criteria/standards developed for evaluating decision aids. Health Expect 17:232-243, 2014

40. Woloshin S, Schwartz LM, Black WC, et al: Women's perceptions of breast cancer risk: How you ask matters. Med Decis Making 19:221-229, 1999

41. Peters E, Diefenbach MA, Hess TM, et al: Age differences in dual information-processing modes: Implications for cancer decision making. Cancer 113:3556-3567, 2008

42. Reyna VF, Nelson WL, Han PK, et al: How numeracy influences risk comprehension and medical decision making. Psychol Bull 135:943-973, 2009

43. Trevena LJ, Zikmund-Fisher BJ, Edwards A, et al: Presenting quantitative information about decision outcomes: A risk communication primer for patient decision aid developers. BMC Med Inform Decis Mak 13:S7, 2013 (suppl 2)

44. Légaré F, Ratté S, Gravel K, et al: Barriers and facilitators to implementing shared decisionmaking in clinical practice: Update of a systematic review of health professionals' perceptions. Patient Educ Couns 73:526-535, 2008

45. Witteman HO, Dansokho SC, Colquhoun H, et al: User-centered design and the development of patient decision aids: Protocol for a systematic review. Syst Rev 4:11, 2015 
46. Abras C, Maloney-Krichmar D, Preece J: User-centered design, in Bainbridge W (ed): Encyclopedia of Human-Computer Interaction. Thousand Oaks, CA, Sage Publications, 2004, pp 445-456

47. Kuniavsky M: Observing the User Experience: A Practitioner's Guide to User Research. New York, NY, Elsevier, 2003

48. Garrett JJ: The Elements of User Experience: User-Centered Design for the Web and Beyond. New York, NY, Pearson Education, 2010

49. Lindgaard G, Chattratichart J: Usability testing: What have we overlooked?Proc SIGCHI Conference on Human Factors in Computing Systems2007:1415-1424, 2007

50. Bastien JM: Usability testing: A review of some methodological and technical aspects of the method. Int J Med Inform 79:e18-e23, 2010

51. Vredenburg K, Mao J-Y, Smith PW, et al: A survey of user-centered design practice. Proc SIGCHI Conference on Human Factors in Computing Systems2007:471-478, 2002

52. Légaré $\mathrm{F}$, Moumjid-Ferdjaoui $\mathrm{N}$, Drolet $\mathrm{R}$, et al: Core competencies for shared decision making training programs: Insights from an international, interdisciplinary working group. J Contin Educ Health Prof 33:267-273, 2013

53. Karsh B-T: Clinical practice improvement and redesign: How change in workflow can be supported by clinical decision support. Rockville, MD, Agency for Healthcare Research and QualityPublication 09-0054-EF, 2009. https://healthit.ahrq.gov/sites/default/files/docs/biblio/090054-EF-Updated_0.pdf

54. Hsiao C-J, Jha AK, King J, et al: Office-based physicians are responding to incentives and assistance by adopting and using electronic health records. Health Aff (Millwood) 32:1470-1477, 2013

55. Lenert L, Dunlea R, Del Fiol G, et al: A model to support shared decision making in electronic health records systems. Med Decis Making 34:987-995, 2014

56. Härter M, van der Weijden T, Elwyn G: Policy and practice developments in the implementation of shared decision making: An international perspective. Z Evid Fortbild Qual Gesundhwes 105:229-233, 2011

57. Scholl I, Koelewijn-van Loon M, Sepucha K, et al: Measurement of shared decision making: A review of instruments. Z Evid Fortbild Qual Gesundhwes 105:313-324, 2011

58. Barr PJ, Elwyn G: Measurement challenges in shared decision making: Putting the 'patient' in patient-reported measures. Health Expect 19:993-1001, 2016

59. Ara R, Brazier J, Sculpher M, et al: A framework for conducting economic evaluations when using patient decision aids in health care decision making. Sheffield, United Kingdom, University of Sheffield EEPRU Research Report 049, 2015. http://www.eepru.org.uk/wp-content/ uploads/2017/11/eepru-report-framework-for-ecomonic-evalutions-re-pdas-2015-049.pdf

60. Kourou K, Exarchos TP, Exarchos KP, et al: Machine learning applications in cancer prognosis and prediction. Comput Struct Biotechnol J 13:8-17, 2014

61. Vickers AJ: Prediction models in cancer care. CA Cancer J Clin 61:315-326, 2011

62. Jensen PB, Jensen LJ, Brunak S: Mining electronic health records: Towards better research applications and clinical care. Nat Rev Genet 13:395-405, 2012

63. Abbasgholizadeh Rahimi S, Menear M, Robitaille H, et al: Are mobile health applications useful for supporting shared decision making in diagnostic and treatment decisions? Glob Health Action 10:1332259, 2017 (suppl 3)

64. van Weert JC, van Munster BC, Sanders R, et al: Decision aids to help older people make health decisions: A systematic review and meta-analysis. BMC Med Inform Decis Mak 16:45, 2016

65. Heart T, Kalderon E: Older adults: Are they ready to adopt health-related ICT? Int J Med Inform 82:e209-e231, 2013

66. Brabers AE, Rademakers JJ, Groenewegen PP, et al: What role does health literacy play in patients' involvement in medical decision-making? PLoS One 12:e0173316, 2017 